\title{
Thelypteris SUbG. AMAURopelta (ThelyPTERIDACEAE) Da EstaÇão Ecológica do Panga, Uberlândia, Minas Gerais, Brasil
}

\author{
Adriana A. Arantes ${ }^{1}$, Jefferson Prado ${ }^{2}$ \& Marli A. Ranal
}

\begin{abstract}
Resumo
(Thelypteris subg. Amauropelta (Thelypteridaceae) da Estação Ecológica do Panga, Uberlândia, Minas Gerais, Brasil) O presente trabalho apresenta o tratamento taxonômico para as espécies de Thelypteris subgênero Amauropelta que ocorrem na Estação Ecológica do Panga. Thelypteridaceae mostrou-se uma das mais representativas da pteridoflora local, com 14 espécies de Thelypteris segregadas em quatro subgêneros (Amauropelta, Cyclosorus, Goniopteris e Meniscium). Na área de estudo, o subgênero Amauropelta está representado por quatro espécies, Thelypteris heineri, T. mosenii, T. opposita e T. rivularioides. São apresentadas descrições, chave para identificação das espécies, comentários, distribuição geográfica e ilustrações dos caracteres diagnósticos.
\end{abstract}

Palavras-chave: samambaias, Pteridophyta, cerrado, flora, taxonomia.

\section{Abstract}

(Thelypteris subg. Amauropelta (Thelypteridaceae) of the Ecological Station of Panga, Uberlândia, Minas Gerais State, Brazil) This paper provides the taxonomic treatment for the species of Thelypteris subgenus Amauropelta in the Ecological Station of Panga. Thelypteridaceae is one of the richest families in the area, with 14 species of Thelypteris segregated in four subgenera (Amauropelta, Cyclosorus, Goniopteris, and Meniscium). In the area the subgenus Amauropelta is represented by four species, Thelypteris heineri, T. mosenii, T. opposita, and T. rivularioides. Descriptions, identification key, comments, geographical distribution and illustrations of diagnostic characters of the species are presented.

Key words: ferns, Pteridophyta, 'cerrado', flora, taxonomy.

\section{INTRODUÇÃO}

Thelypteridaceae é uma das famílias mais ricas em pteridófitas, com cerca de 1.000 espécies, e distribuição subcosmopolita, com a maioria das espécies ocorrendo nas regiões tropical e subtropical (Ponce 1995; Smith \& Cranfill 2002). A família é monofilética e compreende duas grandes linhagens, uma chamada de phegopteróide, mais basal, que inclui os clados Macrothelypteris, Pseudophegopteris e Phegopteris, e a outra, thelypteróide, com os demais clados (Smith \& Cranfill 2002). A classificação da família é controversa, mas há uma tendência do reconhecimento de apenas dois gêneros (Macrothelypteris e Thelypteris), de acordo com o arranjo proposto por Smith (1992), para a flora do Peru. Macrothelypteris é nativo dos trópicos e subtrópicos da Ásia, ilhas do Pacífico, Queensland e África e naturalizado no Novo
Mundo. Thelypteris é subcosmopolita e subdividido em vários subgêneros. Adotandose a proposta de Smith $(1990,1992)$ para a classificação da família, cerca de 100 espécies e cinco subgêneros de Thelypteris (Amauropelta, Cyclosorus, Goniopteris, Meniscium e Steiropteris) ocorrem no Brasil (Arantes et al. 2007a, 2007b).

O presente trabalho é parte do levantamento florístico das pteridófitas da Estação Ecológica do Panga que vem sendo realizado pelo Instituto de Biologia da Universidade Federal de Uberlândia, desde 1986. Neste artigo, parte do tratamento de Thelypteridaceae para a Estação Ecológica do Panga está apresentada, abordando as espécies de Thelypteris, subgênero Amauropelta, com chave de identificação, sinonímias, ilustrações, distribuição geográfica e comentários sobre as espécies. Chaves para gêneros e subgêneros e o

Artigo recebido em 08/2007. Aceito para publicação em 01/2008.

${ }^{1}$ Universidade Federal de Uberlândia, Instituto de Biologia, C.P. 593, 38400-902, Uberlândia, MG, Brasil.

${ }^{2}$ Instituto de Botânica, C.P. 3005, 01061-970, São Paulo, SP, Brasil.

Autor para correspondência: adrianassisa@ hotmail.com 
tratamento taxonômico para Macrothelypteris e Thelypteris subgênero Cyclosorus encontram-se em Arantes et al. (2007a) e os tratamentos taxonômicos para os subgêneros Meniscium e Goniopteris desta mesma área encontram-se em Arantes et al. (2007b).

\section{Material e Métodos}

A Estação Ecológica do Panga (E.E.Panga) é de propriedade da Universidade Federal de Uberlândia e abrange uma área de 409,5 ha, situada a $30 \mathrm{~km}$ ao sul do centro da cidade de Uberlândia, MG, entre as coordenadas $19^{\circ} 09^{\prime} 20^{\prime \prime}-19^{\circ} 11^{\prime} 10^{\prime} \mathrm{S}$ e $48^{\circ} 23^{\prime} 20^{\prime \prime}-48^{\circ} 24^{\prime} 35^{\prime \prime} \mathrm{W}$, a 740-840 m de altitude (Araújo et al. 2002). A área apresenta fitofisionomias comuns do bioma cerrado como campestres (campo úmido e veredas), savânicas (campo sujo, campo cerrado, cerrado s.str.) e florestais (cerradão, mata mesófila semidecídua de encosta e de galeria) (Schiavini \& Araújo 1989).

Ao longo dos 20 anos de estudos no local, os espécimes testemunho foram coletados, herborizados e encontram-se depositados nos Herbários HUFU, SP e UC (acrônimos segundo Holmgren et al. (1990)). Para o presente estudo, foram realizadas novas coletas pontuais na área, nos meses de outubro a dezembro de 2004, a fim de melhorar a amostragem das espécies.

Para as identificações do material foi utilizada bibliografia especializada para o subgênero, incluindo Ponce (1987, 1995), Smith (1974, 1992, 1995a), Mickel \& Smith (2004) e Salino \& Semir (2004). Os nomes de autores de táxons foram abreviados segundo Pichi Sermolli (1996).

As descrições foram elaboradas com base nos caracteres morfológicos dos espécimes coletados na área e, quando necessário, complementadas com material de áreas próximas. As informações sobre a distribuição geográfica foram extraídas da literatura consultada e das etiquetas dos espécimes examinados nos herbários HUFU, SP e UC.

\section{Resultados e Discussão}

O subgênero Amauropelta está representado na área por quatro espécies, Thelypteris heineri, T. mosenii, T. opposita e $T$. rivularioides.

Thelypteris subg. Amauropelta (Kunze) A.R. Sm., Amer. Fern J. 63: 121. 1973. Amauropelta Kunze, Farnkr. 1: 109. 1843. Tipo: Amauropelta breutelii Kunze (= Thelypteris limbata (Sw.) Proctor)

Rizoma ereto, subereto ou reptante. Frondes subdimorfas; lâmina 1-pinado-pinatífida, pinas proximais gradual a abruptamente reduzidas, ápice da lâmina confluente, pinatífido; segmentos oblongos ou lineares, ápice obtuso, agudo ou pungente; nervuras usualmente simples, ocasionalmente furcadas, o par proximal de nervuras dos segmentos adjacentes encontrando-se na margem dos segmentos, acima do sinus; indumento com tricomas aciculares, uni- ou pluricelulares, não ramificados, raramente ausentes. Soros usualmente arredondados, medianos ou submarginais sobre as nervuras; indúsio presente ou ausente; esporângios glabros ou setosos.

O subgênero Amauropelta foi dividido por Smith (1974) em nove seções, baseado nas formas do rizoma, no tipo e distribuição dos tricomas e presença ou ausência de aeróforos, de indúsio e de escamas sobre a costa. Na área de estudo, o subgênero pode ser caracterizado pela presença de pinas reduzidas na base da lâmina, nervuras livres, sendo que as nervuras basais dos segmentos adjacentes unem-se à margem acima do sinus (Fig. 1d), além de esporos com superfície reticulada.

Mais de 200 espécies de Amauropelta ocorrem no neotrópico e este é o maior subgênero, se comparado com os demais da família. Há poucas espécies de Amauropelta na África, Madagascar, Ilhas Mascarenas e Ilhas do Oceano Pacífico e apenas uma no Havaí (Smith 1992).

Algumas espécies são amplamente distribuídas, ocorrendo do sudeste do México até a Bolívia (Smith 1992). A região andina é o principal centro de diversidade, sendo 
conhecidas 60 espécies para o Equador (Smith 1983), 47 para o Peru (Smith 1992) e 57 para toda a Mesoamérica (Smith 1995b). Para a região centro-oeste da América do Sul, excluindo a Bolívia, são conhecidas 40 espécies do subgênero (Ponce 1998). Para o Brasil são listadas 35 espécies, a maioria para os estados das Regiões Centro-Oeste e Sudeste e 20 espécies para a Região Sul (Ponce 1995, 1998). A maior parte das espécies ocorre em bordas de florestas úmidas, ao longo das margens de rodovias, trilhas, riachos e em locais úmidos, especialmente em elevações medianas a altas (Mickel \& Smith 2004).

Para o estado de São Paulo, Salino \& Semir (2004) listaram 22 espécies do subgênero. Comparando-se esses dados com as espécies encontradas na E.E. Panga, as quatro espécies encontradas aqui são de ocorrência comum com o estado de São Paulo. Em relação aos demais levantamentos do subgênero, as espécies Thelypteris opposita e $T$. rivularioides apresentaram distribuição mais ampla; T. opposita com amplitude de ocorrência desde o México até o sul do Brasil e T. rivularioides ocorrendo mais ao sul da América Latina, ou seja, do centro-oeste ao sul do Brasil, Paraguai, Argentina e Uruguai. Thelypteris heineri e T. mosenii apresentam distribuição mais restrita ao centro-oeste e sudeste do Brasil, sendo T. mosenii, encontrada também no Paraguai.

\section{Chave para as espécies de Thelypteris subg. Amauropelta na E.E. do Panga}

1. Face abaxial da lâmina com tricomas uncinados e pluricelulares sobre a raque, costa e nervuras 4. T. rivularioides

1'. Face abaxial da lâmina sem tricomas uncinados e pluricelulares sobre a raque, costa e nervuras.

2. Raque com tricomas aciculares, hialinos ou ferrugíneos, antrorsos, tricomas glandulares ausentes; costa e nervuras com tricomas esbranquiçados; soros sem indúsio; esporângios setosos 1. T. heineri

2'. Raque, costa e nervuras com tricomas aciculares, hialinos, crispados ou hirsutos, tricomas glandulares presentes; soros com indúsio; esporângios glabros.

3. Rizoma ereto; pecíolo curto 1,5-10,2 cm; costa abaxialmente com tricomas crispados e glandulares sésseis 3. T. opposita

3'. Rizoma reptante; pecíolo longo, 12,5-41 cm; costa abaxialmente com tricomas hirsutos e glandulares pedicelados 2. T. mosenii

1. Thelypteris heineri (C. Chr.) C.F. Reed., Phytologia 17: 282. 1968. Dryopteris heineri C. Chr., Repert. Spec. Nov. Regni Veg. 6: 380. 1909. Lastrea heineri (C. Chr) Brade, Bradea 1(22): 222. 1972. Tipo: BRASIL. SÃO PAULO: Campinas, 9.IX.1905, Heiner 540 (holótipo $\mathrm{S}$ n.v.).

Fig. $1 \mathrm{a}-\mathrm{b}$

Rizoma ereto, $1,5-3 \mathrm{~cm}$ diâm., com escamas oval-lanceoladas, $0,3-0,9 \mathrm{~mm}$ compr., castanhas, pubescentes a glabrescentes. Frondes 55-114 cm compr., subdimorfas, as férteis freqüentemente com margens das pinas revolutas; pecíolo $12-22 \times 0,3-0,6 \mathrm{~cm}$, amarelado a castanho, brilhante, escamas presentes apenas na base, moderadamente piloso; lâmina 44-90 cm compr., papirácea a cartácea, profundamente 1-pinado-pinatífida, com 3-5 pares de pinas proximais reduzidas, as mais basais $0,3-1,8 \mathrm{~cm}$ compr., pinas distais gradualmente reduzidas a um ápice pinatífido; raque moderadamente pilosa adaxialmente a densamente pilosa na face abaxial, com numerosos tricomas aciculares, antrorsos, unicelulares, hialinos ou ferrugíneos, 0,4-0,8 mm compr.; pinas 14-32 pares por lâmina, 6$12 \times 1,5-2,3 \mathrm{~cm}$, lanceoladas, sésseis, base cuneada, ápice agudo a longo-cuspidado; nervuras 9-12 pares por segmento; indumento da face abaxial com tricomas aciculares, esbranquiçados, a maioria $0,3-0,4 \mathrm{~mm}$ compr., costa, nervuras e tecido laminar entre as nervuras com tricomas de $0,1-0,2 \mathrm{~mm}$ compr., 
adaxialmente glabrescente ou com tricomas aciculares sobre costa e nervuras. Soros supramedianos, arredondados, sem indúsio; esporângios setosos, com 2-4 tricomas glandulares, receptáculos pubescentes.

Distribuição geográfica: a espécie é restrita às Regiões Centro-Oeste e Sudeste do Brasil, ocorrendo em Goiás, Distrito Federal, Minas Gerais e São Paulo, em matas de galeria e mesófilas semidecíduas, ao longo das margens de rios. Na E.E. Panga é encontrada nas bordas e interior de mata de galeria.

Material examinado: IV.1992, M. A. Ranal 566 (HUFU, SP), 570 (HUFU); IX.2004, A. A. Arantes \& M. A. Ranal 1263 (HUFU), 1265 (HUFU), 1269 (HUFU), 1271 (HUFU), 1273 (HUFU), 1280 (HUFU), 1281 (HUFU), 1283 (HUFU), 1285 (HUFU); X.2004, A. A. Arantes \& M. A. Ranal 1295 (HUFU), 1300 (HUFU), 1323 (HUFU).

Thelypteris heineri e T. mosenii são duas espécies muito semelhantes, principalmente pelo formato das lâminas, com vários pares de pinas proximais abruptamente reduzidas e pinas lanceoladas com ápice agudo. No entanto, Thelypteris mosenii caracteriza-se pelos pecíolos glabros a glabrescentes, ápice das pinas agudo e lâminas, abaxialmente, com tricomas hialinos sobre a raque e glandulares amarelos a alaranjados sobre a lâmina, entre as nervuras (Fig. 1 c-d). Na falta de material fértil destas duas espécies, o tipo de indumento mostrou ser um bom caráter na distinção entre elas.

2. Thelypteris mosenii (C. Chr.) C.F. Reed, Phytologia 17: 294. 1968. Dryopteris mosenii C. Chr., Kongel. Danske Vidensk. Selsk. Skr., Naturvidensk. Math. Afd. ser. 7, 4: 300, fig. 27. 1907. Lastrea mosenii (C. Chr.) Copel., Gen. fil.: 139. 1947. Tipo: BRASIL. MINAS GERAIS: Rio Capivari, Mosén 2161 (holótipo S n.v.).

Fig. $1 \mathrm{c}-\mathrm{d}$

Rizoma reptante, 1-1,5 cm diâm., coberto no ápice por escamas lanceoladas, 0,3-0,9 mm diâm., pilosas. Frondes 45-105 cm compr., subdimorfas; pecíolo 12,5-41 ×0,3-0,6 cm, amarelado, ceroso, glabro a moderadamente piloso na base e freqüentemente com tricomas glandulares amarelados; lâmina 23-66 cm compr., papirácea a cartácea, profundamente 1-pinado-pinatífida, lanceolada, 2-8 pares de pinas proximais extremamente reduzidas, as basais $0,3-1,8 \mathrm{~cm}$ compr., pinas distais gradualmente reduzidas a um ápice pinatífido; raque moderadamente pilosa adaxialmente e densamente pilosa abaxialmente, com tricomas hialinos, 0,3-0,5 mm compr.; pinas $18-27$ pares por lâmina, 7-16 × 1,0-2,3 cm, lanceoladas, sésseis, pinas distais com o lado basiscópico reduzido e o lado acroscópico auriculado, base truncada, margens fortemente revolutas, ápice agudo; nervuras 9-12 pares por segmento; indumento da face abaxial sobre a costa, nervuras e tecido laminar com tricomas hialinos, 0,2-0,3 mm compr., adaxialmente glabrescente, freqüentemente com tricomas glandulares esbranquiçados a alaranjados sobre o tecido laminar. Soros supramedianos, arredondados; indúsio setoso, esporângios glabros; receptáculos pubescentes.

Distribuição geográfica: Thelypteris mosenii apresenta distribuição restrita ao Brasil e Paraguai (Ponce 1998, Salino \& Semir 2004). No Brasil, ela é muito comum no bioma cerrado, ocorre nas matas de galeria e mesófilas semidecíduas de encosta das Regiões CentroOeste (Goiás e Distrito Federal) e Sudeste (Minas Gerais e São Paulo). Na E.E. do Panga, a espécie cresce nas matas de galeria e mesófila semidecídua de encosta.

Material examinado: III.1987, M. A. Ranal 400 (HUFU, SP); V.1987, M.A. Ranal 453 (HUFU, SP); IV.1992, M. A. Ranal 571 (HUFU); V.1992, M. A. Ranal 586 (HUFU, SP); IX.1999, M. A. Ranal 850 (HUFU, SP); XI.1999, M. A. Ranal 920 (HUFU); IX.2004, A. A. Arantes \& M. A. Ranal 1266 (HUFU), 1268 (HUFU), 1270 (HUFU), 1274 (HUFU), 1278 (HUFU); X.2004, A. A. Arantes \& M. A. Ranal 1294 (HUFU), 1298 (HUFU), 1301 (HUFU); XII.2004, A. A. Arantes \& M. A. Ranal 1403 (HUFU), 1404 (HUFU).

Como citado anteriormente, Thelypteris mosenii e T. heineri são duas espécies muito semelhantes. Thelypteris heineri se diferencia de $T$. mosenii pelo rizoma ereto, pela presença de tricomas hialinos ou ferrugíneos, antrorsos na face abaxial sobre a raque, e de tricomas esbranquiçados sobre as nervuras; também pela ausência de indúsio e esporângios setosos (Fig. 1 a-b). 

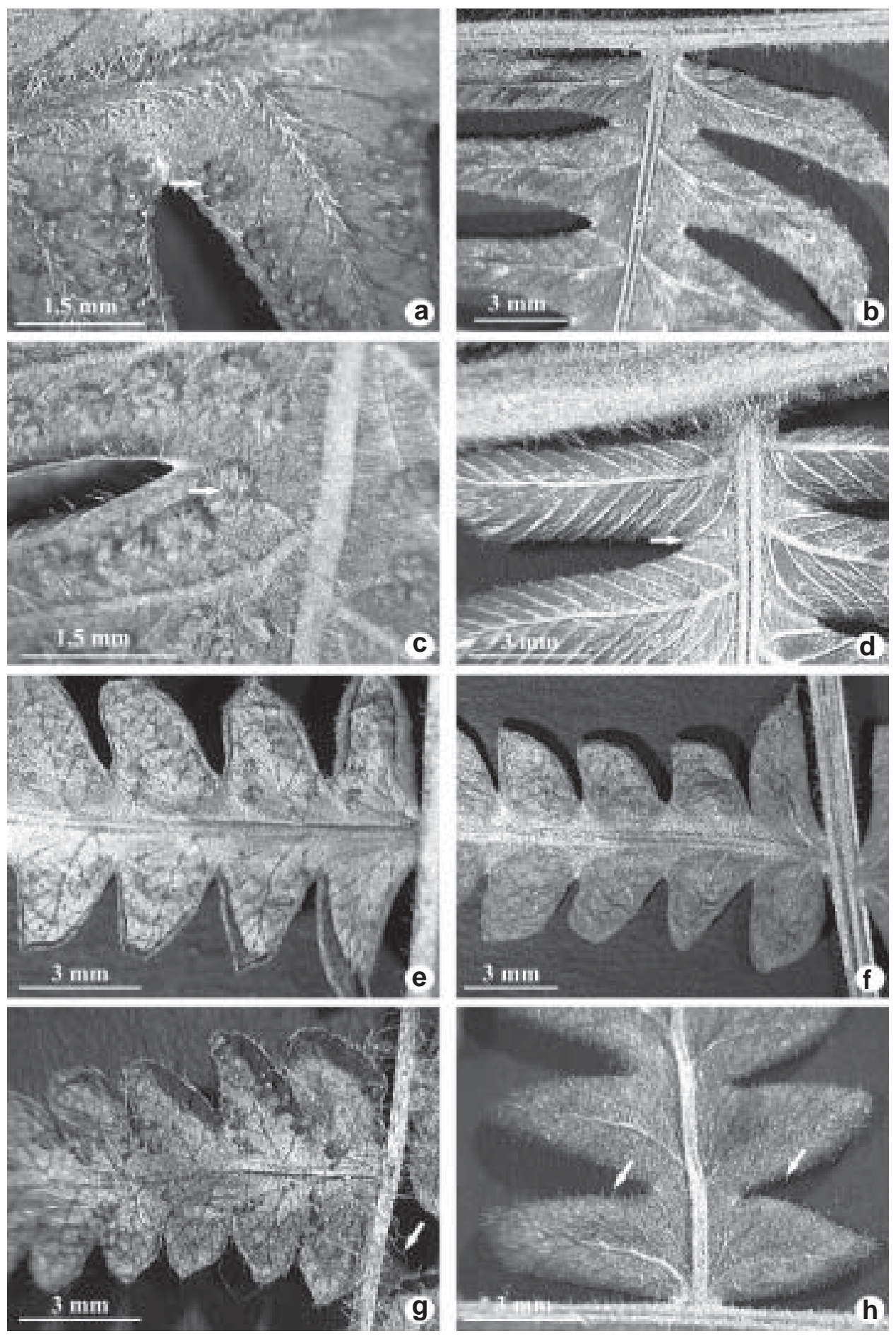

Figura 1 - a-b. Thelypteris heineri (C. Chr.) C.F. Reed. - a. face abaxial da lâmina, detalhe do indumento e do soro sem indúsio; b. face adaxial da lâmina, detalhe do indumento. c-d. T. mosenii (C. Chr.) C.F. Reed - c. face abaxial da lâmina, detalhe do indumento e dos soros com indúsio setoso; d. face adaxial da lâmina, detalhe do indumento e das nervuras. e-f. T. opposita (Vahl) Ching. - e. detalhe da face abaxial da lâmina glabrescente e com margens dos segmentos fortemente revoluta; f. face adaxial da lâmina, detalhe do indumento. g-h. T. rivularioides (Fée) Abbiatti - g. face abaxial da lâmina, detalhe do indumento com tricomas pluricelulares longos; $h$. face adaxial da lâmina, detalhe do indumento com tricomas curtos e nervuras furcadas. (a-b Ranal 566; c-d Ranal 586; e-f Ranal 406; g-h Silva 133). 
3. Thelypteris opposita (Vahl) Ching, Bull. Fan Mem. Inst. Biol. 10: 251. 1941. Polypodium oppositum Vahl, Eclog. Amer. 3: 53. 1807. Dryopteris opposita (Vahl) Urb., Symb. Antill. 4: 14. 1903. Amauropelta opposita (Vahl) Pic. Serm., Webbia 31: 251. 1977. Tipo: MONTSERRAT. Ryan s.n. (holótipo não encontrado; isótipo $\mathrm{BM}$ n.v.). $\quad$ Fig. 1 e-f

Dryopteris rivulorum (Raddi) Hieron., Hedwigia 46: 334. 1907. Lastrea opposita (Vahl) C. Presl var. rivulorum (Raddi) Brade, Bradea 1(22): 196, 223, tab.16, fig. 55. 1972. Tipo: BRASIL. "margines rivulorum prope Rio de Janeiro": Raddi s.n. (holótipo FI n.v.).

Rizoma ereto, 1-2,5 cm diâm., com escamas esparsas, ca. $2 \mathrm{~mm}$ compr., lanceoladas, moderada a densamente pubescente e com tricomas glandulares alaranjados. Frondes 35-80 cm compr., subdimorfas; pecíolo 1,5-10,2 × 0,2-0,4 cm, amarelado, brilhante, enegrecido na sua porção basal, glabrescente ou com tricomas aciculares, 0,1-0,2 mm compr.; lâmina 18-70 cm compr., cartácea a subcoriácea, 1-pinado-pinatífida, lanceolada, 4-12 pares de pinas proximais reduzidas, pinas distais gradualmente reduzidas a um ápice pinatífido; raque abaxialmente glabrescente ou pilosa, os tricomas crispados 0,4-0,6 mm compr.; pinas 20-59 pares por lâmina, 2,6-8,5 × 0,7-1,6 cm, lanceoladas, sésseis, a maioria oposta, base auriculada, margens dos segmentos fortemente revolutas, ápice pungente ou obtuso; nervuras 5-7 pares por segmento; face abaxial com indumento variável, de denso a moderado, freqüentemente com tricomas crispados sobre a costa e nervuras, tricomas glandulares amarelados e brilhantes normalmente sobre as nervuras e tecido laminar e com escamas lineares sobre a costa, face adaxial glabra ou com tricomas esparsos semelhantes aos da face abaxial. Soros supramedianos, arredondados; indúsio glabro ou pubescente, com tricomas glandulares nas margens; esporângios e receptáculos glabros.

Distribuição geográfica: Thelypteris opposita tem ampla distribuição, ocorrendo desde as Antilhas e América Central até a América do Sul. No Brasil, a espécie ocorre em Rondônia, Mato Grosso, Mato Grosso do Sul, Goiás, Distrito Federal, Minas Gerais até Santa Catarina. Na E.E. do Panga ocorre no interior de mata de galeria, de mata mesófila semidecídua de encosta e de veredas.

Material examinado: VIII.1986, M. A. Ranal 384 (HUFU), XI.1986, M. A. Ranal 395 (HUFU); III.1987, M. A. Ranal 402 (HUFU, UC), 406 (HUFU, UC); V.1987, M. A. Ranal 450 (HUFU), 454 (HUFU, UC, SP); IV.1992, M. A. Ranal 567 (HUFU, SP); XI.1998, M. A. Ranal 628 (HUFU, SP); III.1999, M. A. Ranal 649 (HUFU, SP); IV.1999, M. A. Ranal 659 (HUFU, SP), 666 (HUFU, SP); V.1999, M. A. Ranal 731 (HUFU); VII.1999, M. A. Ranal 763 (HUFU, SP), 765 (HUFU, SP), 767 (HUFU), 769 (HUFU, SP), 786 (HUFU, SP), 787 (HUFU), 790 (HUFU, SP), 797 (HUFU); VIII.1999, M. A. Ranal 808 (HUFU, SP), 818 (HUFU), 823 (HUFU, SP); X.1999, M. A. Ranal 874 (HUFU, SP), 885 (HUFU, SP), 893 (HUFU, SP), 901 (HUFU, SP), 908 (HUFU, SP); XI.1999, M. A. Ranal 916 (HUFU, SP), 939 (HUFU, SP), 946 (HUFU, SP), 949 (HUFU, SP), 950 (HUFU, SP), 955 (HUFU, SP); I.2000, M. A. Ranal 992 (HUFU), 998 (HUFU), 1009 (HUFU, SP); II.2000, M. A. Ranal 1024 (HUFU, SP); XII.2004, A. A. Arantes \& M. A. Ranal 1400 (HUFU), 1409 (HUFU).

Thelypteris opposita é muito variável com relação ao indumento. $\mathrm{Na}$ área de estudo pôde-se observar duas formas, uma glabra e outra pilosa. Esta última com indumento abaxial variável, de denso a moderado, com tricomas crispados sobre a costa e nervuras, além de tricomas glandulares amarelados e brilhantes normalmente presentes sobre as nervuras e tecido laminar, e escamas lineares sobre a costa; a face adaxial pode ser glabra ou com tricomas esparsos. De acordo com Smith (1992), esta variação pode estar relacionada com o ambiente onde os indivíduos são encontrados, se sombreados, no interior das florestas ou totalmente ensolarados, como nas margens de rios ou veredas. $\mathrm{Na}$ área de estudo T. rivularioides e T. opposita são espécies que se assemelham pelo porte e forma das frondes. T. opposita difere de $T$. rivularioides pelo rizoma ereto e pela ausência de tricomas pluricelulares no pecíolo e lâmina e nervuras furcadas (Fig. 1 e-f), que estão presentes somente em T. rivularioides (Fig. $1 \mathrm{~g}-\mathrm{h}$ ). 
4. Thelypteris rivularioides (Fée) Abbiatti, Rev. Mus. La Plata, Secc. Bot. 9: 19. 1958. Aspidium rivularioides Fée, Crypt. vasc. Brés. 1: 145, tab.50, fig.1. 1869. Dryopteris rivularioides (Fée) C. Chr. apud Rosenst., Hedwigia 46: 125. 1907. Tipo: BRASIL. RIO DE JANEIRO: s.d., A. F. Glaziou 2358 (isótipo $\mathrm{C}$ n.v.). Fig.1 g-h Nephrodium pseudothelypteris Rosenst., Hedwigia 43: 225. 1904. Dryopteris pseudothelypteris (Rosenst.) C. Chr., Ind. Fil.: 286. 1905. Síntipo: BRASIL. RIO GRANDEDO SUL: Santa Cruz, Campo da Cria, II-1904, Jürgens \& Stier 52 (isossíntipo UC!).

Dryopteris rivularioides (Fée) Rosenst var. umbratica Rosent. Hedwigia 56: 366.1915. Tipo: BRASIL. SÃO PAULO: Lageado, s.d., A. C. Brade 5844 (isótipo UC!).

Dryopteris sinuata Sehnem in Reitz, Fl. Ilust. Catarinense I, ASPI: 242. 1979. Tipo: BRASIL.SANTA CATARINA: Ilha de Santa Catarina, Morro do Antão, 10.I.1948, A. Sehnem 3123 (holótipo PACA n.v.).

Rizoma reptante, $0,25-0,8$ cm diâm., com poucas escamas lanceoladas, $2-3 \mathrm{~mm}$ compr., glabras. Frondes $22-150 \mathrm{~cm}$ compr.; pecíolo $2-25 \times 0,1-0,15 \mathrm{~cm}$, verde-claro a castanhoclaro, brilhante, piloso na base com tricomas uni a pluricelulares, 0,7-2 $\mathrm{mm}$ compr., e escamas semelhantes às do rizoma; lâmina 12,5-120 cm compr., membranácea, profundamente 1-pinado-pinatífida, lanceolada a elíptica, 8-29 pares de pinas por lâmina, 3-7 pares de pinas proximais reduzidas, $0,1-1,7 \mathrm{~cm}$ compr.; pinas distais gradualmente reduzidas a um ápice pinatífido; raque moderadamente pubescente adaxialmente e densamente pubescente abaxialmente, com tricomas uni a pluricelulares, 0,3-8 $\mathrm{mm}$ compr., nas duas faces; pinas linear-lanceoladas, 1,9-7,2 $\times 1$ 1,9 cm compr., sésseis; segmento basiscópico das pinas proximais às vezes auriculados, margens crenadas, ápice obtuso; nervuras 57 pares por segmento, geralmente simples e furcadas no ápice dos segmentos; indumento abaxial composto por tricomas pluricelulares, a maioria $0,3-0,5 \mathrm{~mm}$ compr., sobre a costa, tricomas aciculares unicelulares sobre a cóstula e tricomas uncinados sobre as vênulas e tecido laminar, tricomas glandulares amarelos também presentes sobre o tecido laminar, adaxialmente com tricomas unicelulares aciculares sobre a costa e nervuras. Soros supramedianos, arredondados; indúsio glandular e pubescente na margem, esporângios glabros.

Distribuição geográfica: Thelypteris rivularioides é amplamente distribuída desde as Regiões Centro-Oeste, Sudeste e Sul do Brasil até o Paraguai, litoral da Argentina e Uruguai (Ponce 1995, 1998). No Brasil, ela é citada para os estados de Goiás, Minas Gerais, Rio de Janeiro, São Paulo, Santa Catarina e Rio Grande do Sul e também para o Distrito Federal (Salino 2005). $\mathrm{Na}$ E. E. do Panga é frequientemente encontrada em áreas de solos úmidos ou alagados como nas veredas e matas de galeria.

Material examinado: VI.19992, M. A. Ranal 596 (HUFU); VII.2000, M. A. Ranal 1031 (HUFU); VIII.2000, M. A. Ranal 1032 (HUFU), 1034 (HUFU, SP), 1035 (HUFU), 1036 (HUFU), 1037 (HUFU), 1038 (HUFU), 1039 (HUFU), 1040 (HUFU), 1041 (HUFU), 1043 (HUFU), 1044 (HUFU); X.2000, $M$. A. Ranal 1055 (HUFU), 1067 (HUFU); XII.2000, M. A. Ranal 1077 (HUFU), 1078 (HUFU), 1085 (HUFU), 1090 (HUFU), 1096 (HUFU), 1097(HUFU); I.2001, M. A. Ranal 1099 (HUFU), 1100 (HUFU), 1101 (HUFU); I.2002, M. A. Ranal 1103 (HUFU), 1104 (HUFU), 1105 (HUFU), 1107 (HUFU, SP); XII.2002, M. A. Ranal 1110 (HUFU, UC); X.2004, A. A. Arantes \& M. A. Ranal 1302 (HUFU), 1303 (HUFU); XII.2004, A. A. Arantes \& M. A. Ranal 1381 (HUFU), 1393 (HUFU), 1397 (HUFU), 1411 (HUFU).

Material adicional: BRAZIL. SÃO PAULO: Piratininga, estrada Bauru-Piratininga, rio Batalha, XII.1978, A. T. Silva 133 (SP).

Os espécimes coletados nas áreas mais abertas da E.E. do Panga possuem grande plasticidade de caracteres, como o maior tamanho das frondes e maior freqüência de tricomas uncinados na face abaxial das lâminas. $\mathrm{Na}$ área de estudo, Thelypteris rivularioides e T. opposita são espécies que se assemelham pelo porte e forma das frondes. As diferenças entre elas são discutidas abaixo dos comentários de T. opposita. 


\section{Agradecimentos}

Ao Dr. Alan R. Smith, pelo auxílio nas identificações, pela concessão do espaço físico durante o período em que a primeira autora esteve no UC e pela disponibilidade de bibliografia específica para o desenvolvimento deste trabalho; ao Instituto de Biologia da Universidade Federal de Uberlândia pelo apoio e infra-estrutura.

\section{REFERÊNCIAS BIBLIOGRÁFICAS}

Arantes, A. A.; Prado, J. \&. Ranal, M. A. 2007a. Macrothelypteris e Thelypteris subg. Cyclosorus (Thelypteridaceae) da Estação Ecológica do Panga, Uberlândia, Minas Gerais, Brasil. Revista Brasileira de Botânica 30: 411-420.

Arantes, A. A.; Ranal, M. A. \& Prado, J. 2007b. Thelypteris subg. Goniopteris e Meniscium (Thelypteridaceae) da Estação Ecológica do Panga, Uberlândia, Minas Gerais, Brasil. Hoehnea 34: 121-129.

Araújo, G. M.; Barbosa, A. A. A.; Arantes, A. A. \& Amaral, A. F. 2002. Composição florística de veredas no Município de Uberlândia, MG. Revista Brasileira de Botânica 25: 475-493.

Holmgren, P. K.; Holmgren, N. H. \& Barnett, L. 1990. Index herbariorum. Part 1: The herbaria of the world. 8ed. New York Botanical Garden, New York, 693p.

Mickel, J. T. \& Smith, A. R. 2004. The pteridophytes of Mexico. Memoirs of the New York Botanical Garden 88: 1-1054.

Pichi Sermolli, R. E. G. 1996. Authors of scientific names in Pteridophyta. Royal Botanic Gardens, Kew.

Ponce, M. M. 1987. Revisión de las Thelypteridaceae (Pteridophyta) argentinas. Darwiniana 28: 317-390. . 1995. Las especies austrobrasileñas de Thelypteris subg. Amauropelta (Thelypteridaceae, Pteridofita). Darwiniana 33: 257-283.

1998. Novedades en Thelypteris subg. Amauropelta (Thelypteridaceae) de Brasil y Paraguay. Novon 8: 275-279.
Salino, A. 2005. Thelypteridaceae. In: Cavalcanti, T. \& Ramos, E. E. (orgs). Flora do Distrito Federal, Brasil. Vol. 4. Embrapa Recursos Genéticos e Biotecnologia, Brasília. Pp. 251-294. \& Semir, J. 2004. Thelypteris subg. Amauropelta (Kunze) A.R. Sm. (Thelypteridaceae - Pterophyta) no estado de São Paulo, Brasil. Lundiana 5: 83-112.

Schiavini, I. \& Araújo, G. M. 1989. Considerações sobre a vegetação da Reserva Ecológica do Panga (Uberlândia). Sociedade \& Natureza 1: 61-66.

Smith, A. R. 1974. A revised classification of Thelypteris subgenus Amauropelta. American Fern Journal 64: 83-94 1983. Polypodiaceae- Thelypteridaceae. In: G. Harling \& B. Sparre (eds.). Flora of Ecuador. Swedish Research Council, Stockholm. Pp. 18-148.

1990. Thelypteridaceae. In: Kramer, K. U. \& Green, P. S. (eds.). Pteridophytes and Gymnosperms. In: Kubitzki, K. (ed.). The families and genera of vascular plants. V.1. Springer Verlag, Berlin. Pp. 263-272.

1992. 16. Thelypteridaceae. In: Tryon, R. M. \& Stolze, R. G. (eds.). Pteridophyta of Peru. Part III. Fieldiana, Botany, new series 29: 1-80.

1995a. Pteridophytes. In: Berry, P. E.; Holst, B. K. \& Yatskievych, K. (eds.). Pteridophytes, Spermatophytes: AcanthaceaeAraceae. In: Steyermark, J. A.; Berry, P. E. \& Holst, B. K. (eds.). Flora of the Venezuelan Guyana. Vol. 2.Timber Press, Inc., Portland. Pp. 1-334.

1995b. Thelypteridaceae. In: Davidse, G. (ed.). Flora Mesoamericana. Psilotaceae a Salviniaceae. Universidad Nacional Autónoma de México, México. Pp. 164195.

\& Cranfill, R. B. 2002. Intrafamilial relationships of the thelypteroid ferns (Thelypteridaceae). American Fern Journal 92: 131-149. 